\title{
O PAPEL DO SETOR TÊXTIL E DE CONFECÇÃO BRASILEIRO NA LIDERANÇA DE UM MODELO SUSTENTÁVEL DE DESENVOLVIMENTO
}

\section{THE ROLE OF BRAZILIAN TEXTILE AND APPAREL INDUSTRY IN THE LEADERSHIP OF A SUSTAINABLE DEVELOPMENT MODEL}

\author{
Flavio da Silveira Bruno \\ Professor \\ UERJ - Universidade do Estado do Rio de Janeiro \\ Departamento de Engenharia Industrial \\ Coordenador do Instituto de Prospecção Tecnológica e Mercadológica do \\ SENAI/CETIQT \\ Rua São Francisco Xavier, 524, 20550-013, Rio de Janeiro, Brasil, \\ fone: (55) 2125877156. \\ flavioeana@uol.com.br \\ Ana Cristina Martins Bruno \\ Coordenadora de Pós-graduação, Pesquisa e Extensão \\ Faculdade SENAI/CETIQT \\ Rua Magalhães Castro, 174, 20961-040, Rio de Janeiro, Brasil, \\ fone: (55) 21-25821085; \\ anabruno@ cetiqt.senai.br
}

\begin{abstract}
RESUMO
Este trabalho sintetiza e discute resultados do Estudo Prospectivo Setorial Têxtil e de Confecção Brasileiro, promovido pela ABDI, confrontando-os com iniciativas de enfoque sócio-ambiental e com tendências de consumo consciente no setor. Relacionando-se os resultados do estudo prospectivo de cunho participativo, elaborado em oficinas com atores empresariais, acadêmicos e de instituições governamentais, com a revisão de literatura técnico-científica são extraídas ênfases para uma política de desenvolvimento sustentável do setor que possa servir de referência para outras cadeias e atividades econômicas.
\end{abstract}

Palavras-chave: Inovação sustentável; ramo têxtil e confecção; consumo consciente; estratégia; ACV.

\begin{abstract}
This paper summarizes and discusses the results of the Brazilian Textile and Apparel Prospective Study, promoted by ABDI, confronting them with socio-environmental initiatives and sustainable consumption trends in this industry. The results of the prospective study developed in participatory workshops with business, academic and governmental institutions actors, are related to technical and scientific literature review in order to draw attention to a sustainable development policy to the sector that can be a reference to other value chains and economic activities.
\end{abstract}


Key-words: Sustainable innovation; textile and apparel industry; sustainable consumption; strategy; LCA. 


\section{INTRODUÇÃO}

Ainda sob a sombra da crise financeira mundial, países e regiões procuram avidamente por novas formas de impulsionar e manter seu crescimento econômico e social em um mundo em que a competição global é marcada por preços cada vez mais baixos e condições de trabalho muitas vezes inaceitáveis. Neste ambiente agressivo onde tem prevalecido o darwinismo empresarial, criatividade e inovação voltam à cena como os motores que impulsionarão novos empreendedores a distanciarem-se de seus competidores para satisfazer necessidades sempre mais exigentes dos mercados mais ricos. Em um mundo em que sobrevive o mais adaptado, essas duas dimensões emergem justamente porque induzem os atores empresariais à adaptação ao novo, ao mesmo tempo em que fortalecem sua capacidade de introduzir novos e desconhecidos padrões, rompendo com a ordem estabelecida (SCHUMPETER, 1961, KAPLINSKY, 2004, ARTHUR D LITTLE, 2006).

O acirramento da competição por custos, iniciada após o término do Acordo sobre Têxteis e Vestuário (UNCTAD, 2008), enfatizou no ambiente global a dimensão econômica de desempenho como racionalidade predominante no desenho de estratégias privadas e de políticas públicas de amparo ao setor têxtil e de confecção (TC). A divisão internacional do trabalho e as alterações na base e nos padrões de consumo na última década impulsionaram ainda mais a redução de margens e a queda de preços no setor (GEREFFI, 2005; KAPLINSKY, 2004; SCHOR, 2005). A crise financeira, com reflexos no emprego nos países desenvolvidos, amplificou a voz do protecionismo dissimulado em exigências de controle de impactos indesejáveis da produção sobre aspectos socioambientais (FLANAGAN, 2008; BIRNBAUM, 2009). Sob este amplo domínio reducionista e monocórdio é que as iniciativas de controle e mitigação de externalidades indesejáveis da produção TC têm sido tomadas em sua maioria.

Os preços no mercado mundial de têxteis e de vestuário vêm caindo continuamente desde a década de 1990, intensificando a pressão sobre os custos. A queda contínua de preços deve-se, em grande parte, ao aumento de mobilidade do capital, à disseminação das tecnologias de comunicação e informação, e ao excesso de oferta internacional de força de trabalho, provocado pelo fim da guerra fria e pela entrada de países asiáticos e da Europa do Leste no mundo capitalista. A competição internacional entre países com políticas de desenvolvimento orientadas para a exportação baseada em indústrias intensivas em mão-deobra permitiu que firmas líderes de cadeias globais de valor depreciassem sistematicamente 


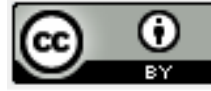

salários e evitassem pagar custos ambientais, tendo seu poder de barganha ampliado pela migração internacional de postos de trabalho para países com menor grau de proteção social e ambiental (KAPLINSKY, MORRIS e READMAN, 2002; SCHOR, 2005; GEREFFI, 1999; 2005).

O reducionismo da abordagem centrada em custos ignora as competências empresariais para diferenciarem-se uns dos outros, princípio ativo em um processo evolutivo das organizações (BALDWIN ET AL., 2004, p.892): submetidas a um regime darwinista de sobrevivência do mais adaptado, devido à nova geografia do ambiente competitivo (BRUNO, 2007, p.90), novas espécies organizacionais surgem enquanto outras são extintas. A dissipação da identidade empresarial no setor é observada pela busca incessante de adaptação no mundo inconstante dos mercados: varejistas se tornam produtores, produtores abrem lojas (BRUNO, 2007, p.278). A perda da identidade permite a analogia com a apropriação do conceito de atenção focal por Sennett (2008, p.107) ao avaliar os efeitos nocivos do excesso de flexibilidade do mundo do trabalho na narrativa de vida das pessoas: "quando falta a crença em que se pode fazer alguma coisa para resolver o problema, o pensamento de longo prazo é suspenso como inútil [...]; os olhos do coelho fixam-se nas patas da raposa". Tal simplificação induz à noção de que apenas países que competirão entre si pelo pior dos mundos da produção sobreviverão à divisão internacional do trabalho.

A crise internacional de setembro de 2008, entretanto, também revigorou o discurso daqueles que crêem no fim do Consenso de Washington e que trazem à tona o trabalho de Karl Polanyi (POLANYI, 2001; GEREFFI, 2005; RODRIK; 2006). O recrudescimento das medidas de proteção ao meio ambiente, à saúde e segurança, aos direitos trabalhistas e aos direitos humanos está na agenda do dia de lobistas do setor nos países mais ricos como forma de evitar os demorados processos de imposição de barreiras nos fóruns internacionais de comércio (FLANAGAN, 2008; BIRNBAUM, 2009; LANDIM, 2009). A julgar pela mídia jornalística, a crise também tem sido causadora de um novo olhar da sociedade mundial sobre a estreita relação entre desenvolvimento e consumo. Consultorias internacionais sinalizam para a emergência de um consumidor mais consciente e para a desaceleração do consumismo como estilo de vida (GFK GROUP, 2009). Mesmo que a precipitada revelação desses sinais pela mídia esteja contaminada de boas intenções, o momento ressalta trabalhos que julgam haver uma falha fundamental no sistema que tem no consumo o fim de toda a atividade econômica (ROBINSON, 2006). A partir da análise da literatura socioeconômica que estuda o 
consumo na sociedade moderna, Robinson (2006) sustenta a tese de que trabalhando e consumindo demais as pessoas sobrecarregam de maneira irracional e insustentável o ambiente em que vivem, de forma tal que sua degradação se dá em uma taxa maior do que aquela com que conseguem adquirir a sensação de bem estar e prosperidade trabalhando mais, ganhando mais e consumindo mais.

No ambiente internacional, após a liberação das forças acumuladas durante a vigência do ATV, passaram a coexistir formas extremas de captação das riquezas do comércio mundial de TC. Países como Bangladesh, onde mais de $90 \%$ de todas as suas exportações são de produtos têxteis, contentam-se em participar de cadeias de valor globais que remuneram seus profissionais com valores 100 vezes menores do que recebem profissionais de mesma atividade em países europeus. No outro extremo, países como a Bélgica conseguem obter valores em dólares por quilograma de têxteis dez vezes maiores que seus concorrentes imediatos em determinados nichos de mercado da moda. A diferença entre os dois mundos, o dos subterrâneos da produção em massa e dos preços sempre em queda, e o da superfície da alta moda e do luxo, está no domínio de conhecimentos-chave e do grau de imersão de cada um em sistemas de inovação que sejam capazes de moldar o futuro.

Condicionadas pelo consumo, pelos códigos de conduta de empresas líderes de cadeias globais, pelas ONGs e convenções internacionais, e pela legislação ambiental de seus países, as empresas do setor têxtil e vestuário foram catapultadas a um novo mundo, em que sua sobrevivência dependerá de sua capacidade de adaptação ao novo ambiente. Liderança ou subordinação nas cadeias globais que levam aos mercados mais ricos depende, cada vez mais, de investimentos de longo prazo que permitam o controle de conhecimentos escassos. Inegavelmente, a capacidade de gerar inovações sustentáveis está entre as competências de maior potencial de diferenciação em futuro próximo. Neste aspecto, a noção schumpeteriana de produção de novas combinações para criação de escassez e distanciamento dos concorrentes (KAPLINSKY, 2004) será traduzida pela capacidade dos sistemas produtivos de incorporar novos atributos aos produtos para que atendam as expectativas de consumidores, cada vez mais conscientes de seu papel na preservação do ecossistema.

Este trabalho analisa os resultados do Estudo Prospectivo Setorial Têxtil e de Confecção (EPSTC) (BRUNO ET AL., 2008) com ênfase na capacitação sustentável do setor. A partir de revisão da literatura selecionada sobre iniciativas ambientalmente responsáveis no setor TC ao longo deste século, e estudos sobre consumo consciente, os resultados do EPSTC 
são avaliados quanto à sua capacidade de contribuir para a formulação de estratégias de desenvolvimento sustentável do setor.

Na seção dois deste trabalho, é oferecida uma síntese dos resultados do EPS-TC, promovido pela Agência Brasileira para o Desenvolvimento Industrial (ABDI). Na seção três, apresenta-se a revisão da literatura sobre iniciativas ambientalmente responsáveis e consumo consciente. A seção quatro discute as ênfases que poderão ser adotadas por políticas de desenvolvimento do setor. Na seção cinco são apresentadas as considerações finais e recomendações para futuros trabalhos.

\section{RESULTADOS DO ESTUDO PROSPECTIVO SETORIAL PARA O SETOR TÊXTIL E DE CONFECÇÃO}

Em meados de 2007, a Agência Brasileira para o Desenvolvimento Industrial (ABDI) encomendou um estudo prospectivo ao Centro de Gestão e Estudos Estratégicos (CGEE) sobre o setor têxtil e de confecção (TC). O estudo contou com o apoio da Associação Brasileira da Indústria Têxtil e de Confecção (ABIT) e teve como objetivo a elaboração de um plano para a priorização de ações de desenvolvimento do setor até 2023. O Instituto de Prospecção Tecnológica e Mercadológica (IPTM) atuou na consultoria especializada, encarregado de refletir a opinião e a visão do comitê gestor do estudo, formado por empresários representativos de todos os elos da cadeia de valor, acadêmicos e representantes de órgãos governamentais. O EPSTC produziu rotas estratégicas e tecnológicas que orientarão o caminho do setor até 2023, construídas participativamente com empresários e stakeholders do setor. Partindo-se de um panorama que descreve o estado atual nas dimensões mercado, tecnologia, talentos, infra-estrutura física, investimentos e ambiente político-institucional, foram elaboradas a visão de futuro e as macro-ações que deverão ser empreendidas até 2023 (BRUNO ET AL., 2008). Os grupos de trabalho sintetizaram em sua visão de futuro que, até 2023, a cadeia têxtil e de confecção brasileira deverá (BRUNO ET AL., 2008, p.68):

Ser reconhecida e admirada pela relevância econômica, política e social de suas atividades, competitiva globalmente e exportadora de destaque no cenário mundial, possuindo como diferencial a utilização ética e sustentável da diversidade de recursos naturais e de competências humanas, enfatizando com criatividade a identidade brasileira, interagindo com outras cadeias produtivas e formando uma rede de valor ágil e versátil, intensiva em conhecimento e integrada desde a concepção até a disposição final de seus produtos - customizados, funcionais e inovadores -, que 




despertem a emoção e atendam às exigências dos diferentes segmentos de consumo.

De maneira geral, as inovações no setor serão empurradas por tecnologias-chave e puxadas pelo consumo-consciente. Especialistas de diversas áreas foram consultados e estabeleceram as tendências que atuarão como vetores de transformação ao longo do tempo que apresentaremos em sete dimensões, a seguir.

a. Novos materiais: o uso intensivo de conhecimento científico no desenvolvimento de novos materiais e estruturas têxteis deverá intensificar, por sua vez, a interação da roupa com o usuário, aumentando as expectativas de funcionalidade do vestuário. $\mathrm{O}$ espectro de funcionalidade amplia-se em suas características estéticas, organolépticas, comunicativas, preventivas, protetoras e complementares: formas, cores e sensações dinâmicas; integração com dispositivos telemáticos; proteção biológica e barreira físico-química; base de armazenamento, transmissão e de geração de energia.

b. Integração com Tecnologias de Informação e de Comunicação: a abordagem de integração com as tecnologias de informação e comunicação (TIC) está intimamente associada à evolução de novos materiais e estruturas têxteis intensivos em conhecimento científico. Neste caso específico, o enfoque concentra-se, entretanto, na integração comunicativa entre consumidor, distribuição, comercialização e sistema de produção, o que torna o consumo, definitivamente, um elo da cadeia de valor.

c. Novas tecnologias de produção: a necessidade de capacitação tecnológica do sistema produtivo estende-se à toda a cadeia de valor, englobando funções técnicas, administrativas e econômicas, para alterar profundamente o perfil das atividades inovativas do setor. A simples aquisição de máquinas e equipamentos, principal atividade inovativa do setor, não será mais suficiente para garantir a ação sobre o mercado global. A própria manutenção da riqueza gerada pelo mercado interno dependerá de uma ação coordenada de capacitação tecnológica liderada pelo Design em consonância com o Consumo. Sobrepondose às tecnologias industriais que procuram aumentar indefinidamente a eficiência e a qualidade dos sistemas físicos de produção estão as tecnologias que aumentam a percepção de valor pelo consumidor.

d. Gestão de ciclo de vida: as tendências de desenvolvimento de produtos sustentáveis que não agridam o meio ambiente e a saúde dos consumidores serão reforçadas pela 


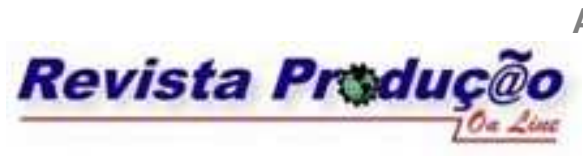

ampliação da base de consumidores conscientes. A integração entre designers, fabricantes de máquinas e produtores de insumos enfatizará ainda mais a importância da P\&D para a fabricação de produtos ecológicos, estendendo o controle por toda a rede e ultrapassando as fronteiras da abordagem restrita ao meio ambiente, para englobar, em um só pacote, questões de segurança e de respeito ao homem.

e. Gestão de cadeias de suprimento: as tendências de mercado referem-se aos movimentos induzidos pela tecnologia incorporada no varejo. Os princípios adotados pelo fast fashion serão adaptados aos novos padrões de consumo e potencializados pela disseminação da tecnologia Radio-Frequency Identification (RFID), aumentando ainda mais a agilidade no controle de estoques por toda a cadeia de valor. Integrando RFID a sensores e materiais inteligentes as roupas do futuro serão verdadeiros sistemas de integração comunicativa entre os hábitos de uso e as empresas de produção, distribuição e comercialização, aproximando seu comportamento das tecnologias de telecomunicações.

f. Liderança do design: pode-se esperar um redirecionamento de produtos orientado cada vez mais por questões sociais, ambientais e econômicas, consolidando o design sustentável, que deixa de ser uma atividade de produção para adotar um papel estratégico. $\mathrm{O}$ designer assume a responsabilidade de humanização de meios e recursos tecnológicos, imbuindo-se da disseminação de uma cultura própria, permeada de valores, e formativa de seus consumidores.

g. Integração de cadeias produtivas: a cadeia produtiva estará imersa na cadeia de valor TC global. Na verdade, a interpenetração de outras cadeias produtivas com a cadeia TC aumentará à medida que as estruturas têxteis - fibras, fios e tecidos - tornarem-se artigos cada vez mais intensivos em tecnologia, multifuncionais. O uso de produtos têxteis em outras áreas e atividades, como engenharia, agricultura e medicina, e sua integração com dispositivos eletrônicos e digitais abre caminho para a total imersão da indústria têxtil em uma dinâmica intensiva em conhecimento, similar a outras indústrias de ponta. Esta tendência pode vir a se configurar em um desacoplamento definitivo da indústria têxtil do perfil atual da cadeia de valor TC.

De acordo com essas tendências, podemos resumir um cenário futuro para o setor:

Em 2023, a cadeia de valor TC brasileira está imersa na cadeia de valor TC global. Na verdade, a interpenetração de outras cadeias produtivas com a cadeia TC aumentou à 

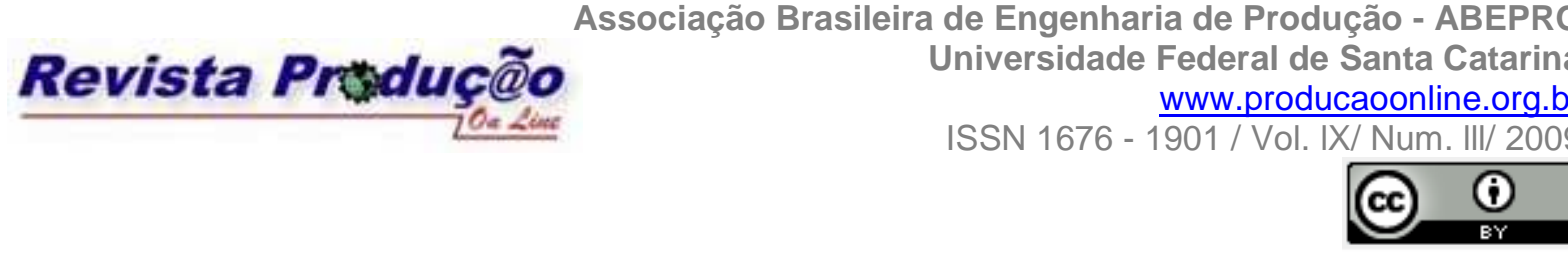

medida que as estruturas têxteis tornaram-se artigos cada vez mais intensivos em tecnologia, multifuncionais. $O$ uso de produtos têxteis em outras áreas e atividades, como engenharia civil, aeronáutica, automobilística, agricultura e medicina, e sua integração com dispositivos eletrônico, fotônicos e digitais abriu caminho para a total imersão da indústria têxtil em uma dinâmica intensiva em conhecimento, similar a outras indústrias de ponta. Esta tendência culminou com o descolamento definitivo da indústria têxtil do perfil atual da cadeia de valor TC (Fig.1). O uso intensivo de conhecimento científico para o desenvolvimento de novos materiais e estruturas têxteis intensificou a interação da roupa com o usuário, aumentando as expectativas de funcionalidade do vestuário. O espectro de funcionalidade ampliou-se. Os produtos orientaram-se para questões sociais, ambientais e econômicas, consolidando o design sustentável, que assumiu um papel estratégico na cadeia, atraindo para si a responsabilidade de humanização de meios e recursos tecnológicos, e imbuindo-se da disseminação de uma cultura própria, permeada de valores éticos e de consciência ecológica.

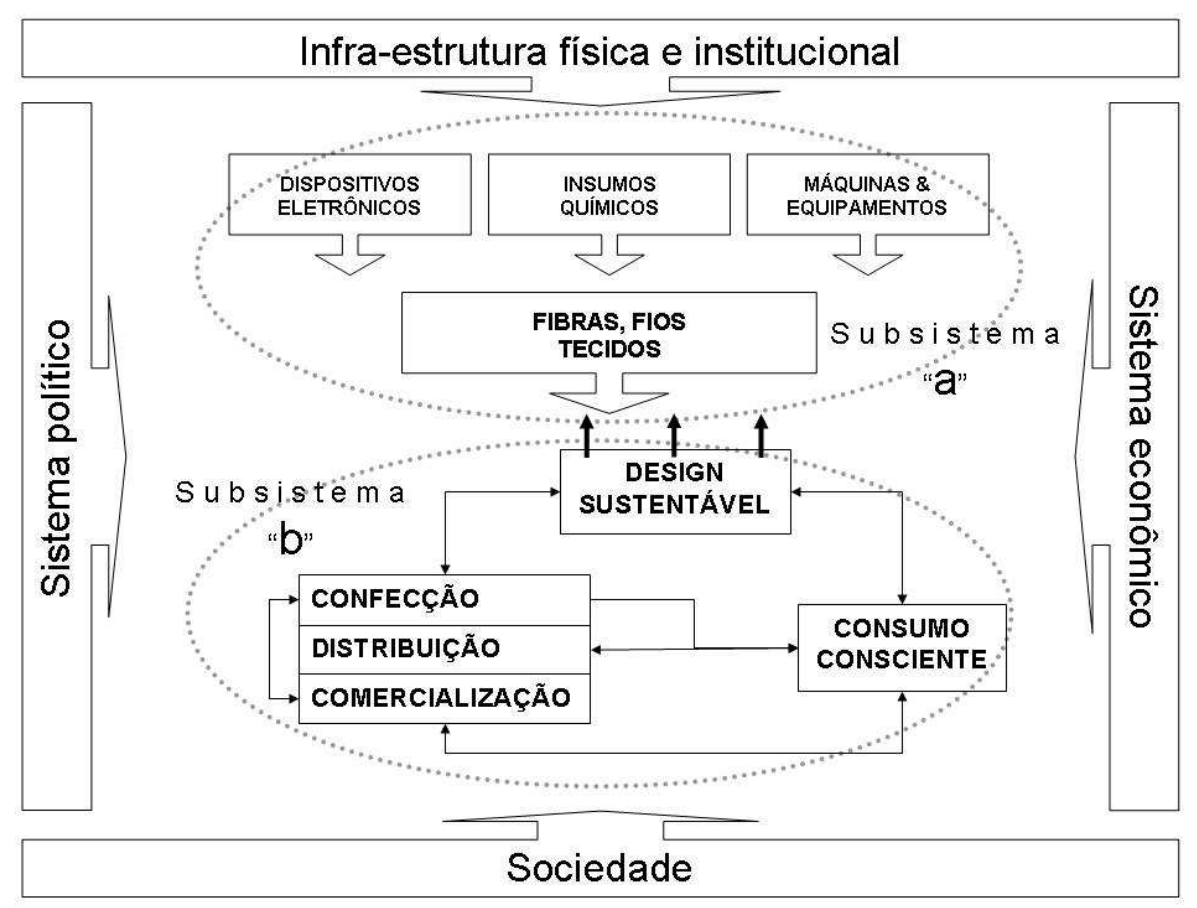

Figura 1: A cadeia de valor TC brasileira em 2023 (BRUNO ET AL., 2008, p.91).

Na figura 1, as empresas líderes do subsistema "a" são inovadoras em produto e processo, intensivas em $\mathrm{P} \& \mathrm{D}$, líderes em conhecimento tecnológico de fabricação. As empresas do subsistema "b" concentram seus investimentos em ativos intangíveis e em tecnologias (e.g. sistemas integrados de gestão e TIC) que lhes garantam a coordenação de suas cadeias de commodities. 
O estudo culminou com a elaboração de um roadmap tecnológico, desenhando as principais vertentes que deverão ser objeto de capacitação tecnológica do setor até 2023 (Fig.2).

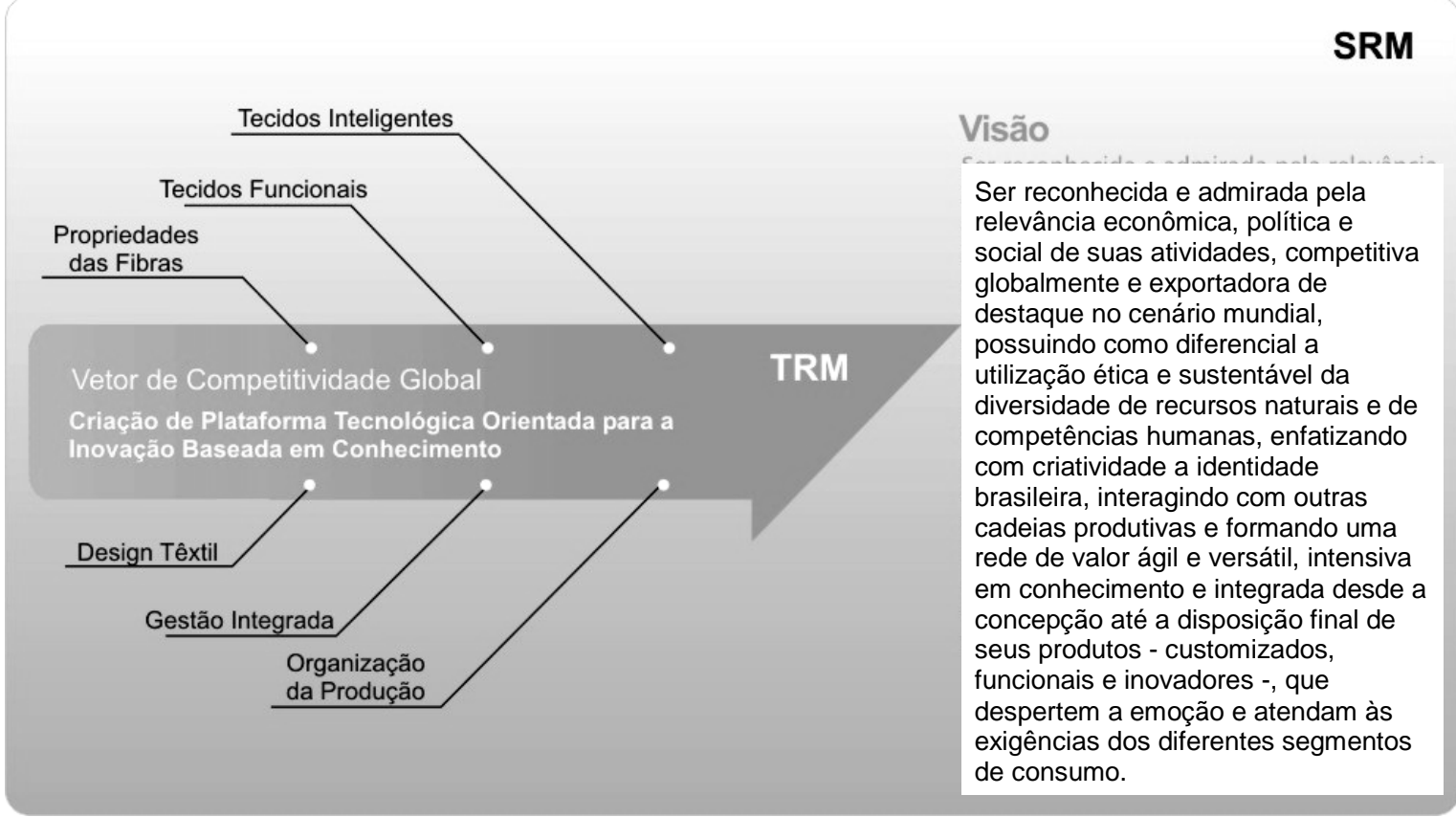

Figura 2: Roadmap tecnológico para o setor: integração das linhas de tecnologia para impulsionar o alcance da Visão de Futuro. Elaborado pelo Centro de Gestão e Estudos Estratégicos (BRUNO ET AL., 2008, p.155).

A introdução de tecnologias no início da cadeia impacta significativamente a competitividade de todo o restante: novas técnicas de fabricação, novos métodos de organização do trabalho e da produção, novos mercados, novas formas de comercialização e novas exigências de qualificação profissional, são aspectos virtualmente dependentes das inovações radicais na base da cadeia.

\section{INICIATIVAS ECO-RESPONSÁVEIS E CONSUMO CONSCIENTE}

Nieminem, Linke, Tobler e Beke (2007) mostraram que novas e emergentes tecnologias limpas assumem posicionamento chave na busca pela emissão zero em processos têxteis. Para identificar os processos mais poluentes, o estudo coletou dados industriais de cinco empresas têxteis européias e utilizou a Análise de Ciclo de Vida (ACV), apoiando o desenvolvimento de novas tecnologias limpas que trarão embutidos novos conceitos de fabricação. Patrocinados pela agência de proteção ambiental dinamarquesa, pesquisadores têm desenvolvido projetos para formação de uma base de dados com fatores de equivalência nas dimensões da $\mathrm{ACV}$ em seis diferentes produtos de vestuário, criando, para cada produto-tipo, 


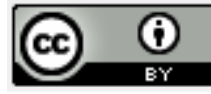

diferentes cenários (LAURSEN, 2007). A construção de cenários promovida pelo uso da ACV implica em contrapor as perspectivas do produtor e do consumidor, avaliando as escolhas de cada um desses grupos. Tal confrontação baseada em atributos de produto e processo inegavelmente amplia e aprofunda o conhecimento da empresa a respeito da essência de sua atividade.

A introdução do consumidor como ator decisório e seletivo é evidenciada em muitos trabalhos que aplicam a metodologia ACV. A redução do consumo de água para a lavagem e de energia elétrica para secagem durante a fase de uso dos produtos, são identificados como aspectos decisivos na escolha dos materiais fibrosos que constituem os produtos têxteis. Há consenso entre autores de que a intensificação e a prolongação do uso de um produto tem impacto favorável no meio ambiente, pois retarda a fabricação de novos produtos feitos de materiais virgens. Deve-se assinalar, entretanto, que um produto pode ser rejeitado antes do fim de sua vida, devido a efeitos visuais indesejáveis (e.g. pilling) ou a mudanças no padrão da moda. Tratamentos antimicrobianos alteram a freqüência de lavagem; fibras sintéticas resistentes prolongam a vida e reduzem o consumo de energia durante a fase de uso; têxteis de algodão consomem menos energia durante a fabricação; diversas combinações possíveis geram cenários que reúnem produtor e consumidor em futuros alternativos compartilhados (KALLIALA e NOUSIAINEN, 1999; HIRSCHL, KONRAD e SCHOLL, 2003; BLACKBURN e PAYNE, 2004; WOOLRIDGE ET AL., 2006; GOERKE ET AL., 2007; SHEN e PATEL, 2008).

Evidências de capacitação como resultado da aplicação de métodos e de novas abordagens para a questão ambiental são encontradas nos trabalhos de Tobler-Rohr (2000), Sondergard, Hansen e Holm (2004), e Goerke et alii (2007). Novos atores, novas percepções e competências emergiram da modernização ecológica deflagrada pela política industrial e ambiental na Dinamarca, na década de 1990, elevando a capacidade para adotar inovações tecnológicas em resposta às demandas ecológicas e ambientais (SONDERGARD, HANSEN E HOLM, 2004). Tobler-Rohr (2000) considera que a ACV permite um entendimento mais profundo dos impactos de produtos e de processos tecnológicos. No Brasil, devem-se notar as aplicações da metodologia por Bastos (2002) para a comparação de produtos em processos de tingimento. As aplicações da metodologia ACV transformam o padrão estratégico. A partir da possibilidade de quantificação de impactos em toda a vida de um produto, o consumidor é integrado à cadeia produtiva, compartilhando e induzindo, ao mesmo tempo, novas 


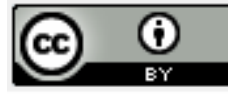

responsabilidades. As trocas decorrentes são transformadoras dos estados mútuos de consciência. O principal decisor deixa de ser apenas usuário; torna-se sujeito atuante na escolha de seu futuro. O estado de consciência é alterado e um novo ator emerge, com diferentes expectativas e necessidades. A decisão de compra interage com a responsabilidade sobre o bem estar futuro. Curto prazo e longo prazo são unidos em um único momento de decisão. Este novo consumidor, mais complexo, utilizará as mesmas informações e conjunto de valores que o sistema de produção, a quem caberá sua operacionalização.

A inovação de caráter sustentável, que alguns autores denominam eco-inovação, é uma dentre diversas abordagens de desenvolvimento sustentável de novos produtos, ou seja, desenvolvimento que atenda necessidades atuais de consumo sem comprometer a satisfação de necessidades de futuras gerações. Projetar produtos sustentáveis requer o balanceamento de aspectos econômicos, ambientais, éticos e sociais (WCED 1987; JONES, 2001).

A conquista de vantagens competitivas em novos mercados que se caracterizam pela exigência de padrões de desempenho empresarial inéditos dependem do lançamento de novos produtos com atributos ambientais. A imagem verde de uma empresa pró-ativa assume valor crescente enquanto esta empresa beneficia-se de vantagens financeiras obtidas pela otimização de processos, redução no uso de materiais e energia, e redução na geração de efluentes (AZZONE e NOCI, 1998; JONES, 2001). O projeto de produtos verdes, em algumas cadeias de produtos, representa uma virtual alternativa para o desenvolvimento de estratégias de negócio baseadas em diferenciação que permitam o aumento de preços e de margens (AZZONE e NOCI, 1998; LAROCHE, BERGERON e BARBARO-FORLEO, 2001).

Se o sistema reduziu a finalidade de toda atividade econômica ao consumo, o consumidor, em contrapartida, tem assumido papel decisivo na premiação das iniciativas verdes de empresas. A mudança gradual de comportamento de consumidores foi evidenciada por Laroche, Bergeron e Barbaro-Forleo (2001) ao analisar trabalhos de outros autores, demonstrando o aumento percentual de pessoas que aceitariam pagar mais por produtos ecologicamente compatíveis. Os autores também identificaram os trabalhos de Berkowitz e Lutternan (1968) e Anderson e Cunninham (1972) como sendo pioneiros no estudo de consumidores responsáveis traçando seu perfil demográfico ainda no início da década de 1970. Os resultados da pesquisa de Laroche, Bergeron e Bárbaro-Forleo ratificam outros estudos sobre a influência do gênero - mulheres estão mais conscientes ambientalmente do 


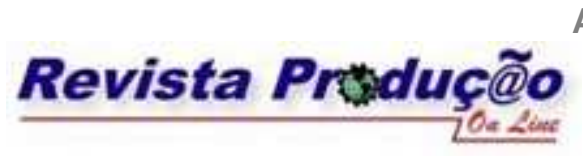

Associação Brasileira de Engenharia de Produção - ABEPRO

Universidade Federal de Santa Catarina

www.producaoonline.org.br

ISSN 1676 - 1901 / Vol. IX/ Num. III/ 2009

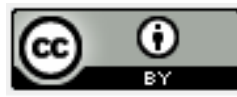

que os homens - e da existência de filhos - casados com filhos não só preocupam-se mais com o futuro de sua prole como parecem estar mais comprometidos com o bem estar dos outros. Idade, nível de educação, salário e status social não mostraram relevância estatística no desejo de pagar mais por produtos mais seguros.

A crise econômica arrefeceu as tendências de consumo mundial, mas seria ingênuo acreditar que comportamentos reforçados ao longo de tantos anos possam ser rapidamente alterados. Schor (2005) discutiu o impacto na sustentabilidade provocado pela redução sistemática de preços e pelo aumento de quantidades e diversidades de produtos consumidos pela população mundial. Até recentemente, o excesso de consumo vinha sendo garantido por um sistema capaz de oferecer cada vez mais alternativas para cada produto, amplificando a capacidade dos indivíduos de perceber valor, ora por inserir novos atributos tecnológicos, ora por disseminar, globalmente, curiosidades e especificidades de culturas locais; extraindo o máximo dos comportamentos globais e locais. É improvável que este ciclo vicioso de consumir em excesso seja interrompido bruscamente. Robinson (2006) avalia que a possibilidade de um indivíduo aumentar sua capacidade de consumir, trabalhando mais para ganhar mais, sobrepuja os ganhos sociais e ambientais que teria por ter mais tempo e por provocar menores danos ao ambiente. Esta falha fundamental do sistema é amplamente explorada por governos que vislumbram saídas de curto prazo para mover da estagnação sociedades com problemas crônicos de desenvolvimento, tornando trabalhadores em consumidores vorazes para gerar mais empregos. A justificativa para o aumento do consumo em países em desenvolvimento ainda apoia-se no argumento de que sociedades de países desenvolvidos produzem muito mais lixo e desperdícios, e consomem muito mais água e energia do que as sociedades mais pobres. Haveria, portanto, justificativa moral para que seja permitido aos mais necessitados desenvolverem-se com base no mesmo modelo insustentável em que os mais ricos prosperaram, enquanto caberia aos últimos as medidas compensatórias, como forma de tributo e penitência. Deve-se considerar, entretanto, que mesmo nos países mais pobres há bolsões de riqueza onde impera o consumismo irresponsável e que servem de referência para os mais pobres, postergando indefinidamente a mudança de conceitos de qualidade de vida nessas sociedades. A mesma retórica fordista reverbera em setores e segmentos através das cadeias globais de valor, transferindo os efeitos da exploração inconsequente do meio-ambiente e do trabalho de algumas sociedades para outras. A questão 


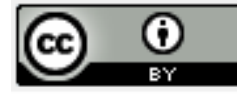

que se impõe resume-se, portanto, em como promover a proteção ambiental sem provocar impactos diretos na geração de novos postos de trabalho.

Se por um lado, não há indícios de um movimento mundial claramente orientado em direção a um comportamento eco-responsável, estudos em países desenvolvidos refletem que, localmente, há mais do que indícios, há evidências. Pesquisa realizada pela Royal Swedish Academy of Engineering Sciences (1995 apud AZZONE, 1998) revelou que os consumidores verdes escandinavos representavam um significativo market share, preferindo produtos que causassem baixo impacto no ambiente. Um estudo promovido pela OCDE (VITALIS, 2002), no entanto, mostrou que se, por um lado, os consumidores de países membros da organização estão cada vez mais interessados em obter informações sobre os impactos indesejáveis da produção dos bens que adquirem, por outro, os valores que estão dispostos a pagar por essas informações não sustentam, por exemplo, os custos dos selos voluntários.

Estudos de ACV mostram que em certos produtos a fase de uso é muito mais importante na possibilidade de redução de consumo de água e energia do que a fase de produção. Além disso, os desafios enfrentados pelo meio ambiente só poderão ser equacionados com a mudança nos padrões comportamentais que associam qualidade de vida a consumo. É preciso encontrar um compromisso entre a exigência de que os países desenvolvidos consumam menos e a necessidade dos países em desenvolvimento de produzir e consumir mais. Essas questões trazem à cena o consumidor como ator central no desenho do futuro (THRONE-HOLST, STO e STRANDBAKKEN, 2007; UNEP, 2001). Nesse contexto, o compartilhamento das responsabilidades entre consumo e produção emerge como alternativa para o desenvolvimento sustentável. A redução da pressão ambiental pode ser conseguida por uma estrada de três vias: produtos e produção verdes, migração da demanda para categorias de consumo de baixo impacto e redução da demanda por materiais. Uma mudança cultural é necessária, entretanto. Para que os negócios desenvolvam culturas congruentes com os valores de seus funcionários, investidores, consumidores e da comunidade entorno, é preciso maior envolvimento de seus stakeholders nas decisões corporativas, propiciando maior fluxo de comunicação para que ocorra um melhor entendimento na definição de valores, objetivos e prioridades compartilhados (TUKKER ET AL., 2008; MICHAELIS, 2003).

A interação entre consumidor e sistema de produção é responsabilidade que vem sendo assumida pela função Design nas organizações. É preciso desenvolver outros sistemas 


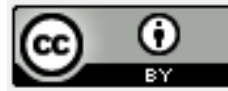

de pensamento, rever as necessidades humanas e as produções locais, desacelerar a moda, implementar inovações sustentáveis, promover o design participativo e pesquisar novos materiais (FLETCHER, 2008). O desafio a ser assumido consiste em criar alternativas que impulsionem novas maneiras de obter satisfação em um cenário de restrição de recursos e de crescimento populacional. A sustentabilidade promove novas e promissoras oportunidades para desenvolver de forma criativa e imaginativa novos conceitos para a cultura do consumo, introduzindo a reavaliação da forma como os produtos são concebidos e como as necessidades são atingidas, anexando ao conceito de eficiência - acessar e possuir os mesmos bens e serviços a partir de menos insumos - o de suficiência - ter a mesma satisfação e bem estar com menos bens e serviços (MARCHAND, 2008; DAVIS, POPOVIC e CROWTHER, 2007).

\section{4. ÊNFASES PARA UMA POLÍTICA DE DESENVOLVIMENTO SUSTENTÁVEL}

Os resultados do EPSTC representam com a maior exatidão que foi possível obter, os anseios, as expectativas e as intenções dos atores que atuaram na formulação das estratégias aqui sintetizadas. Assim como preconiza comitê homólogo, da EURATEX, pode-se afirmar que, para sobreviver na economia do conhecimento, o setor TC brasileiro dependerá da agilidade de sua indústria para produzir inovações, desenvolver os processos mais avançados, flexíveis e eficientes no uso de recursos, e concentrar suas estruturas e operações de negócio na evolução constante das necessidades de seus consumidores. Como ratifica o comitê europeu, pesquisa e inovação assumem papel essencial neste desafio. Sob tais condições, a procrastinação do desenvolvimento sustentável de um sistema de inovações intensivas em conhecimento poderá prolongar ou criar estados de estagnação tão ou mais nocivos à competitividade das empresas brasileiras do que os estados de obsolescência enfrentados no passado, quando a brusca modernização tecnológica dos sistemas de produção provocou o desaparecimento de empresas e empregos.

$\mathrm{Na}$ visão dicotômica do que pertence e do que não pertence ao setor, estabelecem-se pela prática do mercado, caminhos de interpretação que convergem para o consumo. Enquanto se discute a importância da cadeia TC como geradora de empregos de baixa qualificação, as mais recentes inovações tecnológicas em fibras, fios e tecidos imbricam-se no desenvolvimento de novas tecnologias de fabricação, organização da produção, distribuição e comercialização. A ruptura na estrutura já é visível, separando aqueles que liderarão suas 


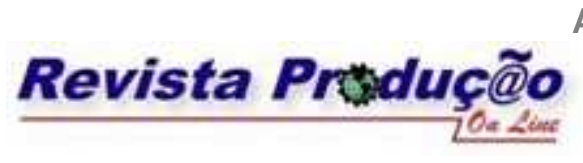

Associação Brasileira de Engenharia de Produção - ABEPRO

Universidade Federal de Santa Catarina

www.producaoonline.org.br

ISSN 1676 - 1901 / Vol. IX/ Num. III/ 2009

cadeias por controle de ativos escassos na base da produção e aqueles que buscarão o controle por intermédio da coordenação das atividades puxadas pelo consumo. Ao cruzar suas linhas com as de outros setores intensivos em tecnologia - como é o caso do modelo conceitual Gina da BMW que substitui a lataria do automóvel por uma cobertura de tecido - o tradicional setor TC vê-se na iminência da ocorrência de um desacoplamento da indústria têxtil da cadeia de valor de confecção e de vestuário. No entanto, se enfatizar a produção de roupas intensivas em tecnologia, o setor voltará a exercer atração sobre aquela indústria pela multiplicação de oportunidades de negócio e pela criação de novos mercados mais rentáveis. Além disso, o cruzamento com outras cadeias introduz novos mercados mais ricos e mais intensivos em tecnologia, com maior disponibilidade de recursos para P\&D. Reduz-se o mercado de roupas tradicionais, ganham-se mercados de roupas de alta tecnologia associadas à indústria de comunicação e do entretenimento.

Inovações radicais na base da cadeia, em fibras e compósitos fibrosos, por exemplo, introduzem novos desafios para designers, mas, sobretudo, introduzem novos desafios para profissionais que trabalham na fabricação de produtos fiados e tecidos, e na montagem de produtos confeccionados. A utilização de insumos de outras cadeias, como sensores e atuadores eletrônicos, e de filamentos fotônicos, por exemplo, gera complexidades inéditas para a montagem de uma peça de roupa, desde sua concepção até sua efetiva fabricação. As costureiras de outrora deverão ser capazes de operar máquinas diferentes em processos de montagem que exigirão outras competências, diversas daquelas que há séculos vêm sendo demandadas de trabalhadores manuais. Portanto, que tipo de emprego o setor está se preparando para suprir no futuro?

Com relação à preocupação com o atendimento do mercado interno, ainda assim, devemos olhar para fora. Na cadeia de valor global de TC, observa-se, continuamente, a dissipação conceitual do que é e do que não é um produto têxtil. Abre-se, dessa forma, o mercado interno para a importação de produtos que não encontram similares nacionais produzidos, por exemplo, por novos entrantes globais, sem qualquer tradição no setor -, anulando-se de vez as iniciativas nascentes de empreendedores com perfil inovador, mas defasados no uso apropriado do ferramental tecnológico necessário. A indecisão em identificar os conhecimentos em que o setor é carente, assim como os limites de sua capacidade para incorporá-los, associada a uma postura conservadora, que postergue a emergência da criação de uma plataforma de inovação, poderão resultar em inexorável perda de oportunidades. O adiamento de uma postura inovativa sustentada em ações coordenadas 


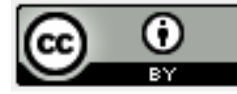

que reúnam governo, academia, sociedade e empresariado enfatizará ameaças e fraquezas do setor, reduzindo suas forças e suas chances de sobrevivência no ambiente global.

Todas as medidas de capacitação tecnológica para que o sistema torne-se mais inovativo, entretanto, não poderão seguir as mesmas trilhas do passado. Produtos, insumos, máquinas, processos, métodos e formas de organização do trabalho estarão cada vez mais condicionados pelo impacto que causam ao meio ambiente e pela observância de critérios éticos e de legislações de amparo ao trabalho. Se inovar era preciso, agora essas inovações deverão seguir critérios ainda mais exigentes em termos do conhecimento envolvido sobre os mínimos detalhes da produção, do suprimento e do consumo. A qualificação e a evolução da consciência ambiental será um fator determinante das novas relações entre sistemas produtivos e consumidores, geradoras de mudanças de comportamentos e do compartilhamento entre os papéis e funções da produção e da sociedade de consumo. A questão cultural revela-se como o esteio de valores em que serão germinadas as mudanças em um complexo ambiente socioeconômico, técnico e político. Novos produtos estão ainda limitados pela capacidade das melhores tecnologias disponíveis de produção propiciarem ecoinovações. Evidencia-se assim, que a possibilidade de produzir produtos de baixo impacto ambiental está condicionada por uma abordagem sistêmica que integre anseios de atores sociais, sistemas produtivos e sistemas de pesquisa e inovação sob um mesmo marco cultural. Declarações de responsabilidade sócio-ambiental e adoção de metodologias de avaliação de impactos ambientais ainda encontram limitações devido ao grau de especificidade e de incertezas que lhes são inerentes. Essas duas características só podem ser resolvidas disseminando e ampliando seu emprego, por intermédio de seu uso sistemático nas organizações produtivas. Há, entretanto, um compromisso a ser estabelecido entre as racionalidades baseadas em fatores econômicos e ambientais. A dedicação de um sistema produtivo às necessidades de informação de metodologias como a ACV capacita esse mesmo sistema: seu autoconhecimento é ampliado, pois envolve aspectos antes ignorados sobre materiais e processos, e sobre suas relações com o ambiente em que são inseridos. A aquisição de novas competências sobre o sistema, assumido na cultura sustentável, amplifica a capacidade de produção de novas combinações em ativos de conhecimentos escassos.

\section{CONSIDERAÇÕES FINAIS}

Mas como o setor poderá assumir papel de liderança no desenvolvimento de iniciativas sustentáveis? Análises de ciclo de vida realizadas em instituições européias com 


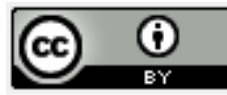

diferentes produtos de vestuário mostram que a fase de consumo é a que maior impacto causa ao meio ambiente. A escolha de fibras e produtos químicos pelos fabricantes, entretanto, está diretamente condicionada pelos tipos de uso que os consumidores finais farão dos produtos, e logo, pelos diferentes níveis de consciência de cada um. É preciso, portanto, que cenários sejam compartilhados entre produtores e consumidores, o que implica na necessária convergência dos estados mútuos de consciência. Para que isto ocorra, é preciso haver trocas entre fabricantes e usuários, que devem compartilhar uma mesma rede social. Se o ambiente produtivo precisa rever seus conceitos e aprofundar seu autoconhecimento, também o consumidor deve se submeter ao mesmo processo. Um conjunto maior de informações tácitas e explícitas precisa ser construído para unir quem produz e quem consome. Nesta transformação, os novos empreendedores de moda assumem papel preponderante, capazes que são de fortalecer simbolicamente e de uniformizar sistemas de valores.

Inovações sustentáveis são essenciais para um mundo que precisa produzir menos, consumir menos, mas, ao mesmo tempo, amplificar a extensão dos benefícios do desenvolvimento, e de gerar mais empregos e melhor qualificação. Seu paradoxo aparente, devido ao abandono necessário do modelo insustentável de consumo em massa, assemelha-se ao paradoxo do desenvolvimento tecnológico e da eliminação de postos de trabalho. É importante lembrar, então, que novas restrições impostas para a produção e consumo criarão, adensarão e multiplicarão áreas de conhecimento, e, assim como sempre ocorre, quando da inserção de novas tecnologias que tornam atividades mais eficientes, inovações sustentáveis gerarão muito mais e melhores empregos.

Trabalhos poderão ser realizados para identificar empiricamente novas competências introduzidas nos sistemas produtivos pela adoção de metodologias de gestão de ciclo de vida. Bases de dados para a composição de inventários de insumos de produtos do setor precisam ser desenvolvidas, permitindo estabelecer e precisar cenários compartilhados entre produtor e consumidor, como no caso do Projeto EDIPTEX, promovido pela agência de proteção ambiental da Dinamarca (cf. LAURSEN, 2007).

\section{REFERÊNCIAS}

ANDERSON, T. Jr., CUNNINGHAM, W.H. The socially conscious consumer. Journal of Marketing, v.36, n.7, 1972, p.23-31, apud LAROCHE, Michel. Targeting consumers who are 
willing to pay more for environmentally friendly products. Journal of Consumer Marketing, v.18, n.6, 2001, p.503-520.

ARTHUR D LITLLE. Clever practices to boost the creative and innovative potencial of regions: inspiration for the districts of creativity. Creativity world forum. Gent, nov, 2006.

AZZONE, Giovanni; NOCI, Giuliano. Seeing ecology and "green" innovation as a source of change. Journal of Organizational Change Management, v.11, n.2, 1998, p.94-111.

BALDWIN, James S. et alii. Modelling manufacturing evolution: thoughts on sustainable industrial development. Journal of Cleaner Production, 2005, n.13, p.887-902.

BASTOS, André Luis Almeida; POSSAMAI, Osmar. Modelo de apoio à decisão para fabricação baseado na avaliação da performance ambiental de produtos e dos objetivos estratégicos da organização. XXII Encontro Nacional de Engenharia de Produção. Curitiba, $23-25$ out. 2002 , p.1-8.

BERKOWITZ, L., LUTTERMAN, K.G.. The traditional socially responsible personality. Public Opinion Quarterly, v. 32, 1968, p.169-85, apud LAROCHE, Michel. Targeting consumers who are willing to pay more for environmentally friendly products. Journal of Consumer Marketing, v.18, n.6, 2001, p.503-520.

BIRNBAUM, David. The arguments against free trade. Just-Style.com. 11 fev. 2009.

BLACKBURN, Richard S.; PAYNE, John D.. Life cycle analysis of cotton towels: impact of domestic laundering and recommendations for extending periods between washing. Green Chemistry, n.6, 2004, p.G59-61.

BRUNO, Flavio S. (org.). Globalização da economia têxtil e de confecção brasileira: empresários, governo e academia unidos pelo futuro do setor. Capítulo 3. Rio de Janeiro: Editora SENAI. 2007.

BRUNO, Flavio da Silveira ET AL.. Estudo Prospectivo Setorial Têxtil e Confecção. Relatório técnico. Centro de Gestão e Estudos Estratégicos. 2008.

DAVIS, Rebekah; POPVIC, Vesna; CROWTHER, Philip. Advancing design activity: catalysts for sustained innovation. In POGGENSPOHL, Sraron, Eds. Proceedings The International Association of Societies of Design Research. Hong Kong Polytechnic University, 2007, p.1-13.

FLANAGAN, Mike. What are the great apparel industry issues for 2009. Just-Style.com, 23 dez 2008.

FLETCHER, Kate. Sustainable fashion and textiles: design journeys. London: Earthscan. 2008.

GEREFFI, Gary. International trade and industrial upgrading in the apparel commodity chain. Journal of International Economics, v.48, 1999, p. 37-70. 


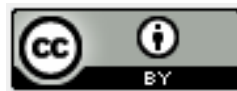

GEREFFI, Gary. The new offshoring of jobs and global development. ILO Social Policy Lectures. Jamaica. 2005.

GFK GROUP. Consumtion crisis? Press releases, 12 fev. 2009. Capturado em http://www.gfk.com/group/press_information/press_releases/003525/index.en.html Acesso em: 12 fev. 2009.

GOERKE et alii. Environmental product declaration as a competitive advantage. Melliand's Textile Report, n.3, 2007, p.E35-37.

HIRSCHL, Bernd; KONRAD, Wilfried; SCHOLL, Gerd. New concepts in product use for sustainable consumption. Journal of Cleaner Production, n.11, 2003, p.873-81.

JONES, E.; STANTON, N. A.; HARRISON, D. Applying structured methods to ecoinnovation: an evaluation of the Product Ideas Tree diagram. Design Studies, v.22, n.6, p.519-542, nov 2001.

KALIALLA, Elija.M.; NOUSIAINEN, Pertii. Environmental profile of cotton and polyester-cotton fabrics. AUTEX Research Journal, v.1, n.1, 1999.

KAPLISNKY, Raphael; MORRIS, Mike; READMAN, Jeff. The globalization of product markets and immiserizing growth:lessons from the south African furniture industry. World Development, v.30, n.7, p.1159-1177, 2002.

KAPLINSKY, Raphael. Sustaining income growth in a globalising world: the search for the Nth rent. Mimeo, Institute of Development Studies, University of Sussex., jan. 2004.

LANDIM, Raquel. Crise eleva barreiras contra produtos do Brasil. Valor Econômico. Caderno Brasil, 5 fev. 2009, p.3.

LAROCHE, Michel; BERGERON, Jasmin; BARBARO-FORLEO, Guido. Targeting consumers who are willing to pay more for environmentally friendly products. Journal of Consumer Marketing, v.18, n.6, 2001, p.503-520.

LAURSEN, Soren Ellebaek. EDIPTEX - Environmental Assessment of Textiles. Coopenhagen: Danish Environmental Protection Agency, 2007.

MARCHAND, Anne; WALKER, Stuart. Product development and responsible consumption: designing alternative for sustainable lifestyles. Journal of Cleaner production, n.16, 2008, p. 1163-69.

MICHAELIS, L.. The role of business in sustainable consumption. Journal of Cleaner Production, n.11, 2003, p.915-21.

NIEMINEM, Eija; LINKE, Michael; TOBLER, Marion; BEKE, Bob Vander. EU COST Action 628: life-cycle assessment (LCA) of textile products, eco-efficiency and definition of best available technology (BAT) of textile processing. Journal of Cleaning Production, n.15, 2007, p.1259-70. 
POLANYI, Karl. The great transformation: the political and economic origins of our time. Massachusets: Beacon Press. 2001.

ROBINSON, Tim. Work, leisure and the environment: the vicious circle of overwork and over consumption. Cheltenham: Edward Elgar Publishing Ltd., 2006.

RODRIK, Dani. Goodbye Washington Consensus, hello Washington confusion. Harvard University. Artigo preparado para o Journal of Economic Literature, 2006.

SCHOR, Juliet. Prices and quantities: unsustainable consumption and the global economy. Ecological Economics, n.55, p.309-320, 2005.

SCHUMPETER, Joseph. The theory of economic development. Oxford: Oxford University Press. 1961.

SENNET, Richard. A corrosão do caráter: consequências pessoais do trabalho no novo capitalismo. Trad. Marcos Santana. Rio de Janeiro: Editora Record. 2008.

SHEN, Li; PATEL, Martin K.. Life Cycle Assessment of polysaccharide materials: a review. Journal of Polymers and the Environment, v.16, n.2, 2008.

SONDERGARD, Bent; HANSEN, Ole Erik; HOLM, Jesper. Ecological modernization and institutional transformations in the Danish textile industry. Journal of Cleaner Production, n12, p.337-52, 2004.

THRONE-HOLST, Harald; STO, Eivind; STRANDBAKKEN, Pal. The role of consumption and consumers in zero emission strategies. Jorunal of Cleaner Production, n.15, 2007, p.1328-36.

TOBLER-ROHR, Marion I.. Life Cycle Assessment of a cotton fabric in textile finishing. Spring 2000.Meeting Program of Fiber Society for the Advancement for Scientific

Knowledge of Fibers, Fiber Based Products and Fibrous Materials. Guimarães, 17-19 maio 2000.

TUCKKER, Arnold et alii. Fostering change to sustainable consumption and production: en evidence based view. Journal of Cleaner Production, n.16, 2008, p.1218-25.

UNITED NATIONS CONFERENCE ON TRADE AND DEVELOPMENT (UNCTAD). The post ATC context. Training module on trade in textiles and clothing. United Nations, New York and Geneva, January 2008.

UNITED NATIONS ENVIRONMENT PROGRAMME (UNEP). Is the future yours? UNEP \& UNESCO research project on youth and sustainable consumption. 2001.

VITALIS, Vangelis. Private Voluntary Eco-labels: trade distorting, discriminatory and environmentally disappointing. Background paper for the Round Table on Sustainable Development meeting which has as its theme "Eco-labelling and Sustainable Development". OECD, 2002. 
WOOLRIDGE, Anne C.; WARD, Garth D.; PHILLIPS, Paul S.; COLLINS, Michael; GANDY, Simon. Life cycle assessment for reuse/recycling of donated waste textiles compared to use of virgin material: an UK energy saving perspective. Resources Conservation and Recycling, n.46, p.94-103, 2006.

WORLD COMISSION ON ENVIRONMENT AND DEVELOPMENT (WCED). Our common future. Transmitted to the General Assembly as an Annex to document A/42/427 Development and International Co-operation: Environment. 1987.

Artigo recebido em 2009 e aceito para publicação em 2009 